\title{
Aufsteiger, Absteiger und ewig "Sonstige“: Klein- und Kleinstparteien bei der Bundestagswahl 2013
}

\author{
Oskar Niedermayer
}

An der Bundestagswahl am 22. September 2013 wollten 58 Parteien und politische Vereinigungen teilnehmen, das heißt sie hatten dem Bundeswahlleiter fristgerecht bis zum 17. Juni ihre Beteiligungsabsicht angezeigt. ${ }^{1}$ In seiner Sitzung am 4. und 5. Juli stellte der Bundeswahlausschuss verbindlich fest, dass neun von diesen Parteien im Deutschen Bundestag oder in einem Landtag seit deren letzter Wahl aufgrund eigener Wahlvorschläge ununterbrochen mit mindestens fünf Abgeordneten vertreten waren. Damit hatten sie die Bedingung des $₫ 18$ Abs. 4 Nr. 1 des Bundeswahlgesetzes erfüllt und konnten ohne weitere Voraussetzungen an der Wahl teilnehmen. Zusätzlich wurden 29 politische Vereinigungen für die bevorstehende Wahl als Parteien anerkannt. Diese konnten ebenfalls - bis zum 15. Juli - Kreiswahl- und/oder Landeslistenvorschläge einreichen, mussten hierzu allerdings Unterstützungsunterschriften beibringen. ${ }^{2}$ Gegen die Ablehnung durch den Bundeswahlausschuss wurde unter anderem von der „Deutschen Nationalversammlung (DNV) “ beim Bundesverfassungsgericht Beschwerde eingelegt, der vom Gericht stattgegeben wurde. Damit waren insgesamt 39 Parteien für die Wahl zugelassen. Letztendlich nahmen aber nur 34 Parteien teil. Die restlichen fünf - CM, DNV, KPD, NM und GMD ${ }^{3}$ - traten aus unterschiedlichen Gründen, vor allem jedoch aufgrund fehlender Unterstützungsunterschriften, nicht an.

Bei der Verteilung der Bundestagsmandate werden nur diejenigen Parteien berücksichtigt, die mindestens fünf Prozent der abgegebenen gültigen Zweitstimmen erhalten oder in mindestens drei Wahlkreisen einen Sitz errungen haben ${ }^{4}$, das heißt: Erhält eine an der Fünf-Prozent-Hürde gescheiterte Partei mindestens drei Direktmandate, so bemisst sich die Gesamtzahl ihrer Mandate nach ihrem Zweitstimmenanteil. War sie jedoch nur in einem oder zwei Wahlkreisen mit ihren Bewerbern erfolgreich, so ist sie nur mit diesen Mandaten

1 Zum Folgenden vgl. die Pressemitteilungen des Bundeswahlleiters vom 18. Juni, 5. Juli und 6. August 2013. Die Information über die DNV wurde dem Verfasser vom Büro des Bundeswahlleiters gegeben.

2 Jeder Kreiswahlvorschlag muss von mindestens 200 Wahlberechtigten des Wahlkreises und jede Landesliste von 1/1.000 der bei der letzten Bundestagswahl Wahlberechtigten des Bundeslandes (höchstens jedoch von 2.000) persönlich und handschriftlich unterzeichnet sein.

$3 \mathrm{CM}=$ Christliche Mitte - Für ein Deutschland nach Gottes Geboten, DNV = Deutsche Nationalversammlung, KPD = Kommunistische Partei Deutschlands, NM = Neue Mitte, GMD = Partei Gesunder Menschenverstand Deutschland.

4 Diese Hürde gilt, wie auch die Bestimmungen über die Unterstützungsunterschriften, seit 1953 nicht für Parteien von nationalen Minderheiten. Politisch relevant wurde diese Ausnahmeregelung bisher allerdings nicht. Die einzige Partei einer nationalen Minderheit, die bisher an Bundestagswahlen teilgenommen hat, ist der Südschleswigsche Wählerverband (SSW), eine Regionalpartei in Schleswig-Holstein, die die Interessen der dänischen Minderheit im Landesteil Schleswig und der „nationalen Friesen“ in Nordfriesland vertritt. Der SSW erhielt 1949, als die Fünf-Prozent-Hürde noch nicht eingeführt war, ein Bundestagsmandat, konnte diesen Erfolg bei den Wahlen 1953 bis 1961 mit 0,1 bis 0,2 Prozent der Stimmen jedoch nicht wiederholen und begrub daraufhin seine bundespolitischen Ambitionen. 
im Bundestag vertreten. ${ }^{5}$ Abbildung 1 zeigt für die bisherigen Bundestagswahlen die Anzahl der mit Landeslisten und Kreiswahlvorschlägen, nur mit Landeslisten und nur mit Kreiswahlvorschlägen an der Wahl teilnehmenden Parteien. Dabei muss beachtet werden, dass die Wähler 1949 nur eine Stimme hatten, so dass die Differenzierung entfällt.

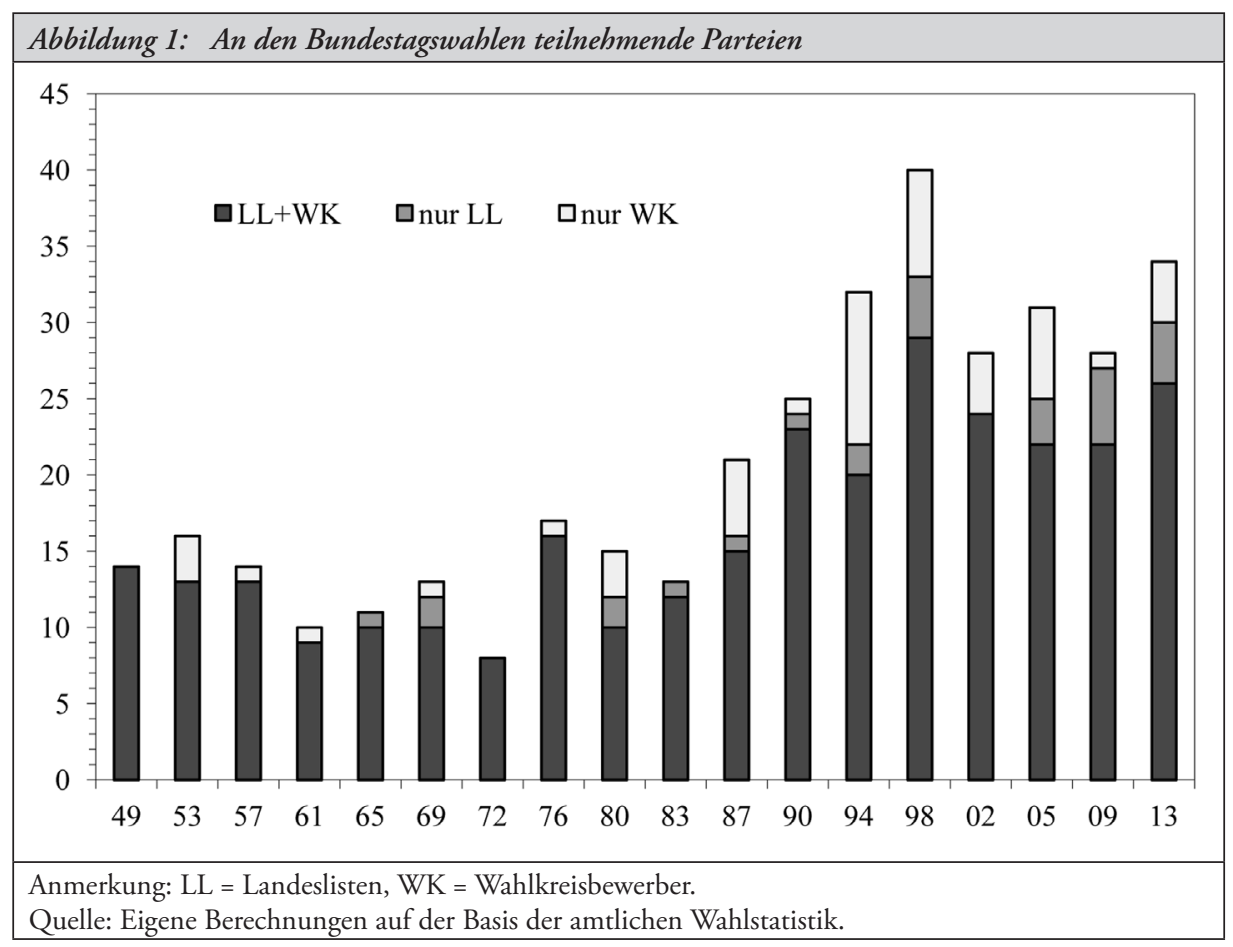

Die Abbildung zeigt, dass bei allen Bundestagswahlen die meisten Parteien sowohl mit Landeslisten als auch mit Kreiswahlvorschlägen an der Wahl teilnahmen. Die höchste Zahl an Parteien, die nur Wahlkreisbewerber aufstellten, gab es 1994 mit zehn, die höchste Zahl an nur mit Landeslisten antretenden Parteien 2009 mit fünf. Die Gesamtzahl der an den Wahlen teilnehmenden Parteien hat sich von 1987 (21) bis 1998 (40) stetig erhöht, ist dann gefallen und erreichte 2013 mit 34 Parteien wieder den zweithöchsten Stand seit 1949.

Von den 34 bei der Wahl angetretenen Parteien wurden diesmal fünf bei der Verteilung der Parlamentssitze berücksichtigt: CDU, CSU, SPD, die Linkspartei und die Grünen. Fast 6,9 Millionen Wählerstimmen blieben ohne parlamentarische Repräsentanz, da 15,7 Prozent der Wähler ihre Zweitstimme einer jener Parteien gegeben haben, die bei der Verteilung der Bundestagsmandate nicht berücksichtigt wurden. Dies wird im Folgenden zum Anlass genommen, die Klein- und Kleinstparteien näher zu betrachten.

5 Für beide Möglichkeiten liefert die damalige PDS ein Beispiel. Von der Wahl 1990 abgesehen, wo es zwei getrennte Wahlgebiete gab, scheiterte die PDS 1994 mit 4,4 Prozent und 2002 mit 4,0 Prozent an der Fünf-Prozent-Hürde. 1994 war sie in vier Wahlkreisen erfolgreich und erhielt insgesamt 30 Mandate, 2002 konnte sie nur zwei Direktmandate gewinnen und war daher nur mit diesen beiden Mandaten im Bundestag vertreten. 


\section{Klein- und Kleinstparteien im Parteiensystem}

\subsection{Definitionsprobleme und Funktionen von Klein- und Kleinstparteien}

In der Parteienforschung besteht keine Einigkeit darüber, wie Klein- und Kleinstparteien zu definieren sind. ${ }^{6}$ Es gibt eine Reihe von Größentypologien von Parteien mit unterschiedlicher Anzahl der Typen, unterschiedlichen Bezeichnungen für die einzelnen Typen und unterschiedlichen Abgrenzungskriterien zwischen den Typen. Die meisten Typologien unterscheiden neben den ,Großparteien' noch zwei weitere Parteitypen. Allerdings ergeben sich in der Regel Probleme der theoretischen Begründung beziehungsweise der Operationalisierung von Typenzuordnungen und -abgrenzungen. Wenn in den Typologien zur Abgrenzung der einzelnen Parteitypen mit der Festlegung von konkreten Schwellenwerten kontinuierlicher quantitativer Indikatoren (zum Beispiel Stimmenanteil) gearbeitet wird, fehlt eine theoretische Begründung für diese Schwellenwerte - es sei denn, sie markieren den Übergang in eine qualitativ andere Rolle im Parteiensystem, wie vor allem das Überschreiten der Fünf-Prozent-Hürde bei Wahlen, die den Übergang zur parlamentarischen Repräsentation markiert. Vermeidet man im Rahmen der Operationalisierung genaue Schwellenwerte und spricht zum Beispiel von hohen/geringen Stimmenanteilen und Mitgliederzahlen, breiter/enger Programmatik oder stärker/schwächer ausgeprägter binnenstruktureller Differenzierung, dann begibt man sich in die Gefahr, bei einigen Grenzfällen Zuordnungsprobleme zu produzieren. Zudem ist zu beachten, dass die Zuordnung einer Partei im Rahmen der Typologie zum einen im Zeitverlauf und zum anderen je nach betrachteter Ebene des politischen Prozesses variieren kann.

Wir gehen im Folgenden von der Bundesebene als der primären Politikebene aus und unterscheiden bezüglich ihrer Einordnung nach der Bundestagswahl vier Parteitypen ${ }^{7}$ : (1) Großparteien: Parteien, mit denen im Bundestag bei Koalitionsregierungen rein rechnerisch mindestens eine minimale Gewinnkoalition mit ihnen als größter Fraktion gebildet werden kann ${ }^{8}$; (2) kleinere Parteien: alle anderen Parteien, die im Bundestag vertreten sind; (3) Kleinparteien: Parteien, die in mindestens einem Landtag beziehungsweise im Europäischen Parlament, aber nicht im Bundestag vertreten sind; (4) Kleinstparteien: Parteien, die auf keiner der drei Politikebenen im Parlament vertreten sind. Diese Kategorie umfasst somit auch jene Parteien, die auf der kommunalen Ebene an Wahlen teilnehmen beziehungsweise nur dort parlamentarisch repräsentiert sind.

Die Kleinstparteien lassen sich zusätzlich noch in relevante und irrelevante Parteien trennen, wobei als Relevanzkriterium die Einbeziehung in die staatliche Parteienfinanzierung dienen kann. Als relevante Kleinstparteien gelten somit im Folgenden alle Parteien, die in der jeweils letzten Wahlperiode mindestens einmal ein Prozent bei Landtagswahlen oder 0,5 Prozent bei Bundestags- beziehungsweise Europawahlen erreicht beziehungsweise über-

6 Zur Definitionsproblematik vgl. ausführlich Uwe Kranenpohl/ Oskar Niedermayer, Kleinstparteien, in: Oskar Niedermayer (Hrsg.), Handbuch Parteienforschung, Wiesbaden 2013, S. 663 - 681, S. $664 \mathrm{ff}$.

7 Dies ist eine modifizierte Version der Typologie in ebenda. Bei mit der Bundestagswahl zeitgleichen Landtagswahlen werden deren Ergebnisse mitberücksichtigt.

8 Gewinnt eine Partei die absolute Mehrheit, dann zählen sowohl sie selbst als auch diejenigen Parteien zu den Großparteien, die rechnerisch eine Minderheitskoalition mit ihnen als größter Fraktion bilden können. 
schritten haben. Da die Typologie auf das Abschneiden der Parteien auf den sekundären Politikebenen abstellt, hat sie eine Schwäche, die zwar äußerst selten auftritt, aber gerade bei dieser Bundestagswahl deutlich wird: Erst kurz vor der jeweiligen Bundestagswahl gegründete Parteien - wie diesmal die Alternative für Deutschland (AfD) - haben geringe Chancen, aus der Kleinst- in die Kleinparteienkategorie aufzusteigen.

Klein- und Kleinstparteien erfüllen - im Rahmen ihrer mehr oder weniger stark beschränkten Möglichkeiten - zunächst die klassischen Parteifunktionen. Darüber hinaus werden vor allem den Kleinstparteien spezifische Funktionen zugeschrieben: Nach Dirk van den Boom ${ }^{9}$ dienen sie für das politische System als „Auffangbecken der ewig Unzufriedenen“, „Entwicklungsfeld neuer politischer Ideen“, „Bewahrer politischer Traditionen“ sowie „Kontrolleure der Mächtigen“ und fungieren für ihre Mitglieder als Ort von „Vereinsmeierei oder Selbstverwirklichung“. Für Jan Köhler ${ }^{10}$ erfüllen sie die Aufgaben der ”Wettbewerbsbelebung“, des „Agenda-Setting“, der „Legitimation“, der „Offenhaltung der innerparteilichen Kommunikation“, der „Trägerorganisationen für Elemente der direkten Demokratie“, der „systemkonformen Äußerungsmöglichkeit für politisches Protestpotenzial“ und der „Bewahrung politischer Traditionen“.

\subsection{Arten und (Miss-)Erfolgsbedingungen von Klein- und Kleinstpartien}

Wie bei ihrer Definition, so gibt es auch bei der Unterscheidung verschiedener Arten von Klein- und Kleinstparteien in der Forschung keinen Konsens. ${ }^{11}$ Kombiniert man zur Typenbildung die Faktoren inhaltliche Orientierung und politische Repräsentation, so lassen sich folgende Typen unterscheiden ${ }^{12}$ : (1) ideologische Randparteien, das heißt links- beziehungsweise rechtspopulistische und -extremistische Parteien (zum Beispiel die MLPD oder die NPD); (2) weltanschauliche Nischenparteien, die die Anhänger bestimmter, wenig verbreiteter Weltanschauungen repräsentieren (zum Beispiel Die Violetten); (3) CleavageRepräsentationsparteien, die einen der Pole einer neu entstandenen, zentralen gesellschaftlichen Konfliktlinie repräsentieren (zum Beispiel die Grünen); (4) Klientelparteien, die die Interessen einer bestimmten, relativ klar abgegrenzten Wählerklientel in verschiedenen Politikbereichen vertreten (zum Beispiel Rentnerparteien); (5) Ein-Themen-Parteien, die in ihrer inhaltlichen Orientierung primär auf ein einziges politisches Thema fixiert sind (zum Beispiel die AfD); (6) personenbezogene Parteien, die in erster Linie den Interessen ihrer Führungsperson dienen (zum Beispiel einige der neuen Parteien in Ostmitteleuropa); (7) Regionalparteien, die auf eine bestimmte Region beschränkt sind und die Interessen der Bürger dieser Region vertreten wollen (zum Beispiel die Bayernpartei); (8) Spaßparteien, die die satirische Parodie von Inhalten und Methoden der anderen Parteien mit zuweilen ernsthaften politischen Positionen verbinden (zum Beispiel Die Partei).

9 Vgl. Dirk van den Boom, Politik diesseits der Macht? Zu Einfluss, Funktion und Stellung von Kleinparteien im politischen System der Bundesrepublik Deutschland, Opladen 1999, S. 264 ff.

10 Vgl. Jan Köhler, Parteien im Wettbewerb. Zu den Wettbewerbschancen nicht-etablierter politischer Parteien im Rechtssystem der Bundesrepublik Deutschland, Baden-Baden 2006, S. 37 ff.

$11 \mathrm{Zu}$ den unterschiedlichen Faktoren, die zur Typenbildung herangezogen werden, vgl. zum Beispiel Paul Lucardie, Zur Typologie der politischen Parteien, in: Frank Decker / Viola Neu (Hrsg.), Handbuch der deutschen Parteien, Wiesbaden 2013, S. 61 - 76.

12 Zum Folgenden vgl. Oskar Niedermayer, Einleitung: Erfolgsbedingungen neuer Parteien im Parteiensystem, in: ders. (Hrsg.), Die Piratenpartei, Wiesbaden 2013, S. 7 - 14. 
Die Bedingungen des Erfolgs beziehungsweise Misserfolgs dieser Parteien, die natürlich in ihrer Relevanz je nach Parteitypus variieren, lassen sich strukturieren, wenn man sich vergegenwärtigt, dass für Parteiensysteme in demokratischen Gesellschaften der freie Wettbewerb zwischen den Parteien konstitutiv ist und jede Art von Wettbewerb durch Angebot, Nachfrage und Rahmenbedingungen bestimmt wird. Die Angebotsseite wird dabei von den einzelnen Parteien, die Nachfrageseite durch die Orientierungen und Verhaltensweisen der Wahlberechtigten gebildet. Der politische Wettbewerb wird zudem durch eine Reihe von Rahmenbedingungen beeinflusst, die von den Akteuren einerseits beachtet werden müssen, andererseits aber auch zum Teil - zumindest für zukünftige Wahlen - beeinflusst werden können.

Auf der Angebotsseite beeinflussen im Einzelnen die folgenden Faktoren den Erfolg oder Misserfolg: (1) die Ressourcen der Partei und ihrer Konkurrentinnen, das heißt die Organisationsstrukturen, die Mitgliedschaft, das Führungspersonal, die Finanzausstattung, die Motivation der Akteure zur Stärkung der Rolle der Partei, die internen Willensbildungsprozesse und die Strategiefähigkeit; (2) die inhaltlichen und organisatorischen Strategien der neuen Partei zur Wählermobilisierung und die Strategien der Konkurrenzparteien gegenüber der neuen Partei; (3) die inhaltlichen Politikangebote der Partei und ihrer Konkurrentinnen, wobei hier vor allem die Verortung der Parteien auf den wesentlichen, den Parteienwettbewerb strukturierenden Konfliktlinien relevant ist. Das deutsche Parteiensystem wird durch zwei zentrale Konfliktlinien geprägt, die beide primär Wertekonflikte darstellen. Im sozio-ökonomischen Bereich ist das der Sozialstaatskonflikt um die Rolle des Staates im ökonomischen Wettbewerb, der als Konflikt um die Grundwerte der sozialen Gerechtigkeit und Marktfreiheit ausgetragen wird. Der zweite Konflikt besteht im sozio-kulturellen Bereich in Gegensätzen hinsichtlich der Gestaltung des gesellschaftlichen Zusammenlebens auf der Basis progressiv-libertärer oder konservativ-autoritärer Wertesysteme.

$\mathrm{Zu}$ den Einflussfaktoren auf der Nachfrageseite des politischen Wettbewerbs gehören: (1) die zentralen gesellschaftlichen Konfliktlinien; (2) das Ausmaß an längerfristigen Parteibindungen; (3) die Interessen und die Organisierbarkeit von Gruppen; (4) die Orientierungen gegenüber dem Spitzenpersonal der Parteien sowie gegenüber einzelnen relevanten Sachthemen.

$\mathrm{Zu}$ den Rahmenbedingungen, die den Erfolg beeinflussen können, gehören: (1) der rechtliche Rahmen, das heißt das Parteien- und Wahlrecht; (2) die föderale oder unitarische Staatsorganisation; (3) das Ausmaß der Unterstützung durch intermediäre Institutionen, das heißt durch Medien, Verbände und soziale Bewegungen; (4) ökonomische, soziale, demographische, innen- und außenpolitische, ökologische und technologische Entwicklungen beziehungsweise Ereignisse, die den Wettbewerb beeinflussen.

Die folgende Analyse des Erfolgs beziehungsweise Misserfolgs vor allem der neuen Parteien bei der Bundestagswahl orientiert sich an diesen Faktoren.

\section{Kleinparteien bei der Bundestagswahl 2013}

An der Bundestagswahl 2013 haben nach der hier vorgenommenen Definition vier Kleinparteien teilgenommen: die FDP (4,8 Prozent der Stimmen), die Piraten (2,2 Prozent), die NPD (1,3 Prozent) und die Freien Wähler (1,0 Prozent). Die FDP war zum Zeitpunkt der Bundestagswahl in neun Landtagen vertreten, die Piraten in vier, die NPD in zwei und die 
Freien Wähler in einem Landtag. ${ }^{13}$ Alle Kleinparteien haben flächendeckend mit Landeslisten teilgenommen, die FDP, die Piraten und die NPD auch mit Wahlkreiskandidaten in allen Bundesländern, wobei die FDP bis auf einen Wahlkreis überall vertreten war. Die Freien Wähler haben in Bremen und dem Saarland keine Wahlkreiskandidaten aufgestellt.

\subsection{Von der dritten Kraft zur marginalen Partei: die FDP14}

Die FDP schien mit dem hervorragenden Wahlergebnis von 14,6 Prozent bei der Bundestagswahl 2009 und der anschließenden Regierungsbeteiligung den Grundstein für eine neue Phase als unangefochtene „dritte Kraft“ im Parteiensystem gelegt zu haben. Dem Höhenflug folgte jedoch 2010 ein jäher Absturz, der sie zur marginalen Partei machte: Sie verlor innerhalb von acht Monaten fast vier Fünftel ihrer Wählerklientel, ein in der deutschen Parteiengeschichte einmaliger Fall einer Regierungspartei. Bis zum Herbst 2013 konnte sie das Blatt nicht mehr entscheidend wenden und scheiterte am 22. September 2013 mit 4,8 Prozent zum ersten Mal in ihrer Geschichte an der Fünf-Prozent-Hürde.

Die Ursachen liegen größtenteils in der Zeit vor der Bundestagswahl von 2009. Die FDP profilierte sich unter Guido Westerwelle als wirtschaftsliberale Alternative zur Unionspolitik in der Großen Koalition. Auch während der im Herbst 2008 einsetzenden Finanzmarkt- und Wirtschaftskrise behielt sie diese Ausrichtung bei, während sich die unionsgeführte Bundesregierung zu staatsinterventionistischem Handeln gezwungen sah. Dies interpretierte ein Teil der wirtschaftsliberal orientierten Unionsanhänger als Verrat am Markenkern der Union und verlieh ihrem Widerspruch durch die Wahl der FDP Ausdruck. Zudem legte Westerwelle die Partei vor der Wahl 2009 in der Außenkommunikation fast ausschließlich auf die Positionierung als Steuersenkungspartei fest. Mit der steigenden Kompetenzzuweisung durch die Wähler im Bereich der Steuer- und Wirtschaftspolitik gelang es den Freidemokraten, über die liberale Kernklientel hinaus auch andere Schichten anzusprechen. Die bei den Wählern geweckten hohen Erwartungen wurden jedoch enttäuscht, da die CDU den weitgehenden Steuersenkungsforderungen der FDP (aber auch der CSU) sehr skeptisch begegnete und angesichts der noch nicht ausgestandenen Wirtschaftskrise und der hohen Staatsverschuldung mehr Wert auf Haushaltskonsolidierung legte. Damit war die Basis für einen Dauerstreit der Koalitionspartner geschaffen. Der einzige Sieg der FDP in diesem Dauerstreit war die - zusammen mit der CSU - Ende 2009 der CDU abgerungene Halbierung des Mehrwertsteuersatzes für das Hotelgewerbe, was jedoch der FDP in den Augen der Wähler wieder das Image der Klientelpartei anheftete.

Einen wesentlichen Anteil am FDP-Absturz hatte zudem die Tatsache, dass ihr Vorsitzender Westerwelle den Rollenwechsel vom aggressiven Oppositionspolitiker zum deutschen Außenminister nicht wirklich vollzog und dadurch den Amtsbonus nicht für sich nutzen

13 Zwei weitere Kleinparteien, die in Landtagen vertreten sind, haben an der Bundestagswahl nicht teilgenommen: die rechtspopulistische Wählervereinigung „Bürger in Wut“, die mit einem Sitz in der Bremer Bürgerschaft vertreten ist, und der SSW (vgl. Fn. 4), der in Schleswig-Holstein mit drei Mandaten im Landtag sitzt und dort sogar an der Regierung beteiligt ist.

14 Für eine ausführliche Version der folgenden Analyse vgl. Oskar Niedermayer, Von der dritten Kraft zur marginalen Partei: Die FDP von 2009 bis nach der Bundestagswahl 2013, in: ders., (Hrsg.), Die Parteien nach der Bundestagswahl 2013, Wiesbaden 2014 (in Vorbereitung). 
konnte, den diese Rolle bei der Bewertung durch die Bevölkerung mit sich bringt. Da der dramatische Ansehensverlust ihres Parteichefs der FDP immer mehr schadete, wurde die innerparteiliche Kritik an ihm ab dem Sommer 2010 immer lauter, und es kam im Dezember 2010 zu einer von FDP-Funktionären immer wieder befeuerten Mediendiskussion um die Ablösung des Vorsitzenden. Der innerparteiliche Aufstand versandete jedoch wieder, nachdem Westerwelle zum freiwilligen Verzicht auf den Parteivorsitz nicht bereit war und aufgrund inhaltlicher wie persönlicher Differenzen in den Reihen des Führungspersonals keine einheitliche gegnerische Front mit einer klaren personellen Alternative gebildet werden konnte.

Deutlich negative Folgen für die FDP hatte zudem die abrupte Kehrtwende der Bundesregierung nach der Reaktorkatastrophe im japanischen Fukushima im März 2011, da sie die treibende Kraft hinter der ein halbes Jahr vorher beschlossenen Laufzeitverlängerung der Atomkraftwerke gewesen war. Die Wahlergebnisse der FDP fielen dann auch entsprechend aus: In Sachsen-Anhalt und Rheinland-Pfalz verfehlte sie den Einzug ins Parlament, und in Baden-Württemberg erhielt sie nur noch halb so viel Zustimmung wie bei der letzten Wahl. Angesichts dieses Desasters war die parteiinterne und mediale Diskussion um Westerwelles Ablösung nicht mehr zu stoppen, und er kandidierte im Mai 2011 nicht mehr für das Amt des Parteivorsitzenden. Die FDP-Führung einigte sich relativ schnell auf Gesundheitsminister Philipp Rösler als neuen Vorsitzenden. Anschließend erfolgte jedoch ein Machtkampf um den Umbau der Partei- und Fraktionsführung. Letztlich musste Wirtschaftsminister Rainer Brüderle seinen Posten zugunsten von Rösler räumen und wurde Fraktionsvorsitzender. Der neue Parteivorsitzende konnte sich jedoch inhaltlich nicht profilieren und stürzte in der Bevölkerungsbewertung im nächsten halben Jahr so stark ab, dass er ab Anfang 2012 negativer bewertet wurde als Westerwelle. Verschlechtert wurde die Lage der Partei noch durch die Niederlagen bei den Landtagswahlen in Mecklenburg-Vorpommern und Berlin im September 2012.

Kurz vor der Berlin-Wahl hatte man noch versucht, mit einer harten Haltung zur europäischen Verschuldungskrise Ressentiments gegen die Griechenlandhilfen zu bedienen. Damit beschwor die FDP eine neue Koalitionskrise herauf und musste sich nun innerparteilich einer Gruppe von marktliberal motivierten Eurokritikern unter der Führung des Abgeordneten Frank Schäffler erwehren, die einen Mitgliederentscheid über die Haltung der Partei zur Einrichtung des unbefristeten europäischen Stabilitätsmechanismus (ESM) durchsetzte. Noch bevor das Ergebnis feststand, trat der zu den jungen Hoffnungsträgern der Partei gezählte Generalsekretär Christian Lindner zurück. Damit sahen viele der Kommentatoren auch die programmatische Neuausrichtung der FDP gescheitert und Rösler wurde ein baldiges politisches Ende vorhergesagt. Das knappe Scheitern des Mitgliederentscheids rettete ihn zwar, kurz darauf machten jedoch neue Putschgerüchte die Runde. Als zukünftiger Vorsitzender wurde Rainer Brüderle gehandelt, der sich in der Rolle als Fraktionsvorsitzender als neuer starker Mann der Liberalen profiliert hatte. Als Rösler jedoch in der Frage des am 18. März 2012 zu wählenden neuen Bundespräsidenten eine Machtprobe mit Angela Merkel riskierte und die FDP auf den auch von SPD und Grünen unterstützten Joachim Gauck festlegte, gewann er in den Augen seiner Kritiker wieder an Statur. Allerdings verlor er sie sofort wieder, als er sich nach der Wahl in aller Öffentlichkeit über Merkels Agieren lustig machte, die Landtagswahl im Saarland am 25. März mit einer dramatischen Niederlage endete und auch die in der ersten Maihälfte 2012 anstehenden nächsten Landtagswahlen verloren zu gehen drohten. 
Mit einer sich explizit von der Bundespartei und ihrem Vorsitzenden distanzierenden Strategie konnte die Partei jedoch mit Wolfgang Kubicki in Schleswig-Holstein wenigstens den Verbleib im Landtag sichern und mit Christian Lindner in Nordrhein-Westfalen sogar in der Wählergunst zulegen. Rösler interpretierte dies als gemeinsamen Erfolg, und die innerparteilichen Kritiker wagten den Putsch wieder nicht. Es schien jedoch ausgemacht zu sein, dass man ihn bei einem Scheitern bei der Landtagswahl in Niedersachsen im Januar 2013 stürzen würde. Dies wurde umso wahrscheinlicher, als der Machtkampf zwischen ihm und seinen Kritikern kurz vor der Wahl erneut eskalierte. Da sich die niedersächsische CDU jedoch nur bei einem Verbleib der FDP im Landtag Chancen auf eine Fortsetzung der CDU-geführten Landesregierung ausrechnete, förderte sie den Versuch der FDP, sich durch taktische „Leihstimmen“ CDU-naher Wähler vor der Niederlage zu retten. Diese Strategie hatte einen unerwartet großen Erfolg: Statt eine drastische Niederlage einstecken zu müssen, konnte die FDP ihren Stimmenanteil sogar steigern, während die CDU deutlich verlor und die Mandatsmehrheit von Schwarz-Gelb im Landtag knapp verfehlt wurde.

Der Wahlerfolg stärkte Philipp Rösler. Der nutzte die Gunst der Stunde und bot sofort nach der Wahl seinem Widersacher Rainer Brüderle an, nicht nur Spitzenkandidat für die Bundestagswahl, sondern auch Parteivorsitzender zu werden. Dabei kalkulierte er, dass Brüderle der Mut fehlen würde, kurz nach einer gewonnenen Wahl den „Königsmörder“ zu spielen. Mit dieser Einschätzung lag er richtig, und daher beschloss die FDP-Führung am 21. Januar 2013, mit einer Doppelspitze aus dem Spitzenkandidaten Brüderle und dem Parteivorsitzenden Rösler in den Bundestagswahlkampf zu ziehen. Kurz nach seiner Nominierung durch den Parteivorstand warf eine Journalistin Brüderle vor, ihr gegenüber an einer Hotelbar anzügliche Bemerkungen gemacht zu haben. Dies löste eine breite öffentliche Sexismusdebatte aus und schadete seinem Ansehen, auch wenn sich die Partei mit ihm solidarisch zeigte. Hinzu kam, dass Brüderle wegen eines Sturzes mit Knochenbrüchen von Mitte Juni bis Mitte August für den Wahlkampf ausfiel. Auch nach seiner Genesung schaffte er es nicht, über die Kernklientel der FDP hinaus bei den Wählern zu punkten.

Inhaltlich sendete die FDP-Führung in der Vorbereitung des Wahlprogramms bezüglich ihrer Positionierung im Sozialstaatskonflikt teilweise widersprüchliche Signale aus: Einerseits hielt man bei der Euro-Rettung marktfreiheitliche Prinzipien hoch, wandte sich daher gegen jegliche Form von Euro-Bonds und die Einführung einer Finanztransaktionssteuer und forderte innenpolitisch den Abbau der so genannten kalten Progression im Einkommensteuertarif sowie die schrittweise Abschaffung des Anfang der 1990er Jahre als befristete Sondersteuer eingeführten Solidaritätszuschlags. Andererseits wurde statt Steuersenkungen nun die Haushaltskonsolidierung mit oberster Priorität versehen, und vor allem wurde mit der Formel von der „fairen Entlohnung“ und von der Leistungsgerechtigkeit auch am unteren Ende der Lohnskala der Weg für eine branchenspezifische und regionale Ausweitung von Lohnuntergrenzen geebnet, die Rösler noch ein paar Wochen zuvor vehement abgelehnt hatte. Damit versuchte die FDP, sich dem gesellschaftlichen Mainstream anzupassen und das Image der sozialen Kälte loszuwerden. Mit dem Beschluss zu den Lohnuntergrenzen verlor man jedoch ein Alleinstellungsmerkmal im Parteiensystem, das für die liberale Kernklientel aus dem Mittelstand entscheidend war. Auf der zweiten zentralen Konfliktlinie des deutschen Parteienwettbewerbs, dem Konflikt zwischen progressiv-libertären und konservativ-autoritären Werten, wollten sich die Liberalen mit der Ablehnung schärferer Sicherheitsgesetze, der Zulassung der doppelten Staatsbürgerschaft und der Durchsetzung der generellen rechtlichen Gleichstellung gleichgeschlechtlicher eingetrage- 
ner Lebenspartnerschaften mit der traditionellen Ehe wieder deutlicher progressiv-libertär positionieren. Auf dem Programmparteitag am 4. Mai wurde dieser Kurs - nach zum Teil kontroverser Diskussion - im Sinne der Parteiführung beschlossen. Weder die personellen noch die inhaltlichen Veränderungen halfen der FDP jedoch, aus dem Umfragetief herauszukommen.

In der zweiten Julihälfte gab Kanzlerin Merkel den Freidemokraten durch ihr Machtwort zur Beibehaltung des Solidaritätszuschlags über 2019 hinaus die Gelegenheit, in Abgrenzung zum Koalitionspartner und den Oppositionsparteien eine neue Steuersenkungsdebatte zu entfachen und sich im Sinne ihrer Kernklientel zu profilieren. Munition für den eigenen Wahlkampf lieferte zudem der politische Gegner: In Reaktion auf die umfangreichen Steuererhöhungsbeschlüsse der Grünen und der SPD konzentrierte die FDP den Wahlkampf unter Brüderles Ägide in traditioneller Weise auf die ökonomisch motivierten Stammwähler im Mittelstand. Es gelang ihr jedoch nicht, den in den Augen der Wähler verloren gegangenen „Markenkern“ im Bereich der Steuer- und Wirtschaftspolitik wieder zu etablieren. Zudem geriet die Positionierung auf der gesellschaftspolitischen Konfliktlinie, das heißt das Herausstellen der FDP als Bürgerrechtspartei, in den Hintergrund.

Auf dem Wahlkonvent am 12. September legte sich die FDP offiziell auf eine Koalition mit der Union fest und schloss alle anderen Bündnisoptionen aus. Gleichzeitig setzte sie verstärkt auf die Warnung vor einer Regierungsbeteiligung der Linkspartei. Eine Woche vor der Bundestagswahl bekam der Wahlkampf einen empfindlichen Dämpfer: Bei der bayerischen Landtagswahl wurde die FDP von der Regierungspartei zur außerparlamentarischen Oppositionspartei. Die Führung verbreitete Endzeitstimmung und warb jetzt unverhohlen um Zweitstimmen von taktisch wählenden Unionsanhängern. Im Gegensatz zu früheren Bundestagswahlen stieß diese Strategie bei der Unionsführung jedoch nach den negativen Erfahrungen aus Niedersachsen auf deutlichen Widerstand. Dennoch wurde in den letzten Tagen vor der Wahl allgemein davon ausgegangen, dass die Partei zwar dramatisch an $\mathrm{Zu}-$ stimmung verlieren würde, es aber gerade noch in den Bundestag schaffen könnte, da alle Umfrageinstitute der FDP in ihren Prognosen Werte zwischen fünf und sechs Prozent voraussagten.

Am Wahlabend wurden die Erwartungen der Liberalen und ihrer Anhänger bitter enttäuscht: Die Partei stürzte auf 4,8 Prozent ab und schied daher aus dem Bundestag aus. Selbst in ihrer traditionellen Hochburg Baden-Württemberg reichte es nur für 6,2 Prozent gegenüber 18,8 Prozent im Jahr 2009, und im Osten der Republik landete sie bei 2,7 Prozent. Das Schicksal der FDP zeigt, dass angesichts der gestiegenen Flexibilität der deutschen Wählerschaft selbst eine Partei, die die Geschicke der Bundesrepublik von Anfang an mitgeprägt hat, vor einem dramatischen Absturz nicht geschützt ist. Die FDP hat die Erwartungen ihrer Wähler enttäuscht, deren Vertrauen verspielt, ihren Markenkern verloren. Diese Probleme konnte sie im Wahlkampf nicht durch eine von den Wählern positiv bewertete neue Spitzenmannschaft sowie durch überzeugende inhaltliche Angebote auffangen.

Am Tag nach der Wahl kündigte der gesamte Bundesvorstand seinen Rücktritt an, und auf einem außerordentlichen Parteitag am 7./8. Dezember 2013 wurde im Anschluss an eine Debatte über die Fehler im Wahlkampf eine neue Führung gewählt. Neuer Parteivorsitzender wurde Christian Lindner, der auch sein Personaltableau für das Präsidium durchsetzen konnte. Insbesondere gelang es dem Eurokritiker Frank Schäffler nicht, zum stellvertretenden Vorsitzenden gewählt zu werden. Lindner will seiner Partei keine grundlegende Kursänderung verordnen, steht aber eher für einen sozialliberal angehauchten Liberalismus, 
der sich auch in der prinzipiellen koalitionspolitischen Öffnung zur SPD und den Grünen ausdrückt. Dieser Kurs missfällt seinen innerparteilichen Kritikern, allen voran dem sächsischen Partei- und Fraktionsvorsitzenden Holger Zastrow, der seit längerem einen deutlich marktliberaleren Kurs der Partei mit der Kernbotschaft eines schlankeren Sozialstaats fordert, und Frank Schäfler, der den von Lindner weiterhin für prinzipiell richtig gehaltenen Eurorettungskurs aus derselben Grundhaltung heraus ablehnt. Die Positionierung zur Eurorettung und zur Europäischen Integration insgesamt ist angesichts der am 25. Mai 2014 anstehenden Wahl zum Europäischen Parlament für die Partei die zentrale inhaltliche Frage der nächsten Monate. Wenn es gelingt, sich in Abgrenzung zur Union auf der einen und zur AfD auf der anderen Seite den Wählern gegenüber als eigenständige Kraft zu präsentieren und ein respektables Wahlergebnis zu erzielen, ist ein erster Schritt hin zum Ziel des Wiedereinzugs in den Bundestag getan. Dies wird jedoch ein steiniger Weg werden. Die FDP muss in Zukunft mit radikal eingeschränkten personellen Ressourcen auskommen, und in ihrer neuen Führung sind nur wenige überregional profilierte Köpfe vertreten. Auch die finanziellen Mittel sind stark betroffen, da durch den Wegfall der Fraktionsgelder und die deutlich geringeren Zahlungen aus der staatlichen Parteienfinanzierung die vorher schon angespannte Finanzlage noch kritischer wird. Zudem steht die FDP vor der schwierigen Aufgabe, als außerparlamentarische Opposition Medienaufmerksamkeit zu generieren und den Wählern zu vermitteln, dass sie als liberale Partei im Parteiensystem wieder gebraucht wird.

\subsection{Wechselbad der Gefühle: die Piraten}

Die Piratenpartei Deutschland wurde am 10. September 2006 in Berlin gegründet ${ }^{15}$, wovon allerdings außerhalb der Netzgemeinde kaum jemand Notiz nahm. Bei ihren wenigen Landtagswahlteilnahmen bis zum Januar 2009 erhielt die neue Partei nur zwischen 0,2 und 0,5 Prozent der Stimmen. Das Ereignis, das sie aus ihrem Schattendasein herausholte, lieferte kurz darauf die Bundesregierung mit der Debatte um ein Gesetz zur Bekämpfung der Kinderpornografie in Kommunikationsnetzen. Von der folgenden Diskussion über die Gefahr einer damit drohenden schleichenden Internetzensur konnten die Piraten politisch profitieren und erreichten bei der Europawahl am 7. Juni 2009 mit 0,9 Prozent einen Achtungserfolg. Kurz danach wurden die letzten Landesverbände der Partei gegründet, so dass sie jetzt eine flächendeckende Organisationsstruktur aufwies. Zudem erlebte sie einen Mitgliederboom. Die gestiegene Organisationskraft und die weiter bestehende Medienaufmerksamkeit halfen ihr, die notwendigen Unterstützungsunterschriften für die Teilnahme an der Bundestagswahl zu sammeln. Über einen sehr guten Online-Wahlkampf gelang es den Piraten, vor allem ihre Kernwählerschaft aus der netzaffinen Jugend optimal zu mobilisieren und ein Wahlergebnis von zwei Prozent zu erzielen. Nach der Wahl herrschte in der

15 Zur Frühphase der Piraten vgl. ausführlich Oskar Niedermayer, Die Piraten im parteipolitischen Wettbewerb: von der Gründung Ende 2006 bis zu den Wahlerfolgen in Berlin 2011 und im Saarland 2012, in: ders., (Hrsg.), Die Piratenpartei. Wiesbaden 2013, S. 29 - 62. Zum weiteren Verlauf bis nach der Bundestagswahl vgl. ders. / Carsten Koschmieder, Steiler Aufstieg und tiefer Fall: die Piraten, in: Oskar Niedermayer (Hrsg.), Die Parteien nach der Bundestagswahl 2013, a.a.O. (Fn. 14). 
Partei zunächst Aufbruchsstimmung, die in der Folgezeit jedoch enttäuscht wurde. Die neue Koalition aus CDU/CSU und FDP setzte das Netzsperrengesetz aus, die Medienaufmerksamkeit ging zurück, und man war immer noch in Geldnot. Die Partei wurde durch interne Streitigkeiten geschwächt, und die Landesverbände waren oft noch zu schwach, um einen effektiven Wahlkampf führen zu können, so dass man bei den folgenden sieben Landtagswahlen vom Frühjahr 2010 bis zum Herbst 2011 mit Ergebnissen von 1,4 bis 2,1 Prozent überall die Träume vom „Entern“ der Landtage begraben musste.

Dies änderte sich erst mit der Berliner Abgeordnetenhauswahl im September 2011, wo die Piraten mit 8,9 Prozent der Stimmen einen Sensationserfolg feiern konnten. Die Gründe für das gute Abschneiden waren vielfältig und zum Teil berlinspezifisch. ${ }^{16}$ Entscheidend war jedoch, dass die Partei deutlich über ihren bisherigen netzpolitischen „Markenkern“ hinausging. Im Mittelpunkt stand als zentrale Wertkategorie die Forderung nach mehr Transparenz und Partizipation in der Politik. Damit griff sie die Grundprinzipien auf, die auch für ihre parteiinternen Willensbildungs- und Entscheidungsprozesse gelten und die Piraten für viele - gerade junge - Bürger interessant machten. Der Erfolg in Berlin bescherte den Piraten einen Medienhype und hob sie in den bundesweiten Umfragen über die Fünf-Prozent-Hürde. Dies trug wesentlich dazu bei, dass die Partei bei der auf den März 2012 vorgezogenen Wahl im Saarland mit 7,4 Prozent erneut ein sehr gutes Ergebnis erzielen konnte und auch dort in den Landtag einzog. Im Mittelpunkt ihres Wahlkampfs stand wiederum die Forderung nach einem neuen Politikstil. Hinzu kam, dass viele Wähler die Piraten noch nicht klar im Parteiensystem verorten konnten und diese daher prinzipiell für enttäuschte beziehungsweise unzufriedene bisherige Anhänger aller anderen Parteien wählbar wurden. Getragen von ihren Wahlerfolgen und einer weiterhin sehr ausgeprägten Medienunterstützung gelang es der Partei auch bei den im Mai 2012 stattfindenden Landtagswahlen in Schleswig-Holstein und Nordrhein-Westfalen problemlos, die Fünf-ProzentHürde zu überwinden, so dass sie nun in vier Landtagen vertreten waren.

Da die Piraten auch in den bundesweiten Umfragen im Frühjahr 2012 zum Teil zweistellige Werte erzielten, schien die Möglichkeit in greifbare Nähe gerückt, im Herbst 2013 den Sprung in den Bundestag zu schaffen. Schon im Herbst 2012 rutschten sie jedoch unter die Fünf-Prozent-Marke. Bei der Landtagswahl im Januar 2013 in Niedersachsen kamen sie nur noch auf 2,1 Prozent, und ihre bundesweiten Umfragewerte waren danach meist so niedrig, dass sie von den meisten Instituten gar nicht mehr gesondert ausgewiesen wurden. Auch die bayerische Landtagswahl brachte mit 2,0 Prozent keine Verbesserung, und bei der Bundestagswahl eine Woche später landeten die Piraten bei 2,2 Prozent.

$\mathrm{Zu}$ diesem Niedergang hat eine ganze Reihe von Faktoren beigetragen. Auf der Angebotsseite des politischen Wettbewerbs sind zunächst die heftigen innerparteilichen Auseinandersetzungen um die inhaltliche und organisatorische Ausrichtung zu nennen. Inhaltlich stritt man um die Frage, ob die Partei mit Rekurs auf ihren Markenkern, die Netzpolitik, eine Ein-Themen-Partei bleiben oder sich breiter aufstellen sollte. Unter den Befürwortern einer inhaltlichen Verbreiterung gab es wiederum keine Einigkeit vor allem über die Positionierung im Sozialstaatskonflikt. Organisatorisch ging es um die Frage, ob man das bezüglich der Willensbildungs- und Entscheidungsprozesse an den Prinzipien der Transparenz, Inklusion und Entgrenzung orientierte, an möglichst flachen Hierarchien ausgerichtete und

16 Vgl. hierzu ders., Die Berliner Abgeordnetenhauswahl vom 18. September 2011: Grün war nur die Hoffnung, die Realität ist rot-schwarz, in: ZParl, 43. Jg. (2012), H. 1, S. 18 - 35, S. 25. 
den Amtsinhabern statt einer politischen Führungsrolle eine bloße Moderatorenfunktion zuweisende Organisationsverständnis aufrecht erhalten oder sich in Richtung einer „normalen" Partei entwickeln sollte. Diese gravierenden internen Konflikte, die noch durch persönliche Animositäten innerhalb des Bundesvorstands - vor allem bezogen auf den politischen Geschäftsführer Johannes Ponader - und zwischen Bundesvorstand und Mitgliedern vor allem der Berliner Landtagsfraktion verschärft wurden, lähmten die Partei. Sie verhinderten den Aufbau eines strategischen Zentrums zur Wahlkampfsteuerung und machten bei der Kampagnenvorbereitung und -durchführung einen zielführenden Einsatz der - begrenzten - innerparteilichen Ressourcen unmöglich. Inhaltlich führten sie auf den Parteitagen, die bei den Piraten keine Delegiertentreffen, sondern Vollversammlungen auf Bundesebene sind, zu stundenlangen fruchtlosen Diskussionen, die in eine unausgereifte Programmatik und unklare Botschaft an die Wähler mündeten. Personell hatten sie zur Folge, dass die Partei kein bekanntes, medienwirksames, führungsstarkes Personal ins Rennen schickte: Die 16 Spitzenkandidaten in Gestalt der die jeweiligen Landeslisten anführenden Personen waren völlig unbekannt und blieben es bis zur Wahl auch. Die zusätzlich als Sprachrohr und Ansprechpartner für bestimmte Politikbereiche vorgesehenen Personen traten öffentlich nicht in Erscheinung. Zudem hatten die Piraten durch die schlechte Zahlungsmoral ihrer Mitglieder und den Mangel an Spenden für eine flächendeckende Kampagne außerhalb des Internets zu wenig finanzielle Ressourcen. Neben den innerparteilichen Problemen trug die Tatsache, dass sie ihr Alleinstellungsmerkmal verloren, zu ihrem Niedergang bei. Mit der NSA-Datenspähaffäre bot sich in der Frühphase des Wahlkampfes eine optimale Gelegenheit, den Wählern die zentralen Anliegen der vermehrten Transparenz, des Datenschutzes und der Stärkung der Bürgerrechte anhand eines konkreten Themas nahezubringen. Da aber auch alle anderen Oppositionsparteien diese Argumentationslinien aufgriffen, konnten die Piraten für sich selbst nur geringe Medienaufmerksamkeit generieren.

Auf der Nachfrageseite des politischen Wettbewerbs führten die monatelangen heftigen inneren Querelen dazu, dass die Partei von den Wählern zunehmend als hauptsächlich mit sich selbst beschäftigte und nicht mehr ernst zu nehmende Chaostruppe wahrgenommen wurde. Da ihre Verortung auf der sozio-ökonomischen und sozio-kulturellen Konfliktlinie unklar blieb, konnten die Wähler zudem nicht erkennen, wofür die Piraten inhaltlich eigentlich stehen. Hinzu kam, dass sie die hoch gesteckten Erwartungen, die sie bei ihren Wählern bezüglich einer neuen, von hoher Transparenz und umfassender Partizipation geprägten „Politik 2.0" geweckt hatten, in ihrer parlamentarischen Arbeit enttäuschten. Die Landtagsfraktionen mussten in vielen Fällen erkennen, dass sie sich den traditionellen Regeln der parlamentarischen Demokratie nicht entziehen konnten, und zudem lieferten sie oft ein genauso zerstrittenes Bild wie die Bundespartei. All dies schreckte potenzielle Randwähler immer mehr ab, und da die Umfragewerte - soweit sie überhaupt an die Öffentlichkeit gelangten - von der Fünf-Prozent-Hürde weit entfernt waren, wollte man auch keine Stimme an eine chancenlose Partei verschenken. Damit wurden die Piraten auf ihre netzpolitische Kernwählerschaft zurückgeworfen. Da dieses Politikfeld jedoch keine zentrale gesellschaftspolitische Konfliktlinie darstellt, ist hierüber nur eine kleine Zahl von Wählern zu mobilisieren.

Im Übrigen hatten sich die Rahmenbedingungen des Parteienwettbewerbs vor allem durch den schon sehr frühzeitigen Verlust der Medienunterstützung gravierend verschlechtert. Ab Sommer 2012 ging die Berichterstattung über die Piraten deutlich zurück, und der Tenor kehrte sich ins Negative um. Die Partei, die anfangs von vielen Journalisten als eine den traditionellen Politikbetrieb aufmischende Heilsbringerin gefeiert wurde, verlor ihren 
„Welpenschutz“. Auch aufgrund der Enttäuschung der eigenen Erwartungen konzentrierte man sich zunehmend auf die Probleme der Partei, und diese lieferte durch ihre heftigen innerparteilichen Auseinandersetzungen genügend Material für kritische Betrachtungen. Im Wahlkampf unterblieb dann weitgehend die negative Berichterstattung, das heißt die Piraten wurden von den Medien ignoriert.

\subsection{Bundespolitisch marginal und vom Verbot bedroht: die NPD}

Die 1964 gegründete rechtsextreme Nationaldemokratische Partei Deutschlands (NPD) zog in der zweiten Hälfte der 1960er Jahre in sieben Landtage ein und scheiterte bei der Bundestagswahl von 1969 mit 4,3 Prozent nur knapp an der Fünf-Prozent-Hürde. An diese Erfolge konnte sie jedoch in der Folgezeit nie mehr anknüpfen. Zum Zeitpunkt der Bundestagswahl 2013 war sie in den Landtagen von Mecklenburg-Vorpommern (6,0 Prozent, fünf Mandate) und Sachsen (5,6 Prozent, acht Mandate) vertreten, auf der Bundesebene blieb sie mit 1,3 Prozent (2009: 1,5 Prozent) jedoch eine marginale Partei.

Im Vorfeld der Bundestagswahl 2013 befand sich die NPD in einem desolaten Zustand. Ihre Mitgliederzahl war seit Jahren rückläufig, und sie hatte gravierende finanzielle Probleme, die ihre Kampagnenfähigkeit stark beeinträchtigten. Die Ende 2010 erfolgte Fusion mit der Deutschen Volksunion (DVU) hatte weder personell noch in Bezug auf die Handlungsfähigkeit eine Verbesserung gebracht. Ihre so genannte Vier-Säulen-Strategie, mit dem Kampf um die Köpfe, um die Straße, um die Parlamente und um den organisierten Willen den demokratischen Verfassungsstaat umfassend unter Druck zu setzen, zeigte keine Erfolge. Auch dem im November 2011 gewählten neuen, in der Partei umstrittenen Vorsitzenden Holger Apfel gelang es mit seinem auf eine gemäßigtere Außendarstellung zielenden Konzept der „Seriösen Radikalität“ nicht, der Partei bessere Wahlergebnisse zu verschaffen. Die NPD musste in sechs der sieben Landtagswahlen bis zur Bundestagswahl teilweise deutliche Stimmenverluste hinnehmen und ist - abgesehen von ihren regionalen Hochburgen in Sachsen und Mecklenburg-Vorpommern - auch auf der Landesebene eine marginale Partei.

Im Bundestagswahlkampf setzte die NPD ihr geschlossen rechtsextremistisches Weltbild wieder mit dem üblichen provokativen Kommunikationsstil um, der nichts mehr von einer argumentativen Mäßigung erkennen ließ: Man versuchte mit unverhohlener Ausländerfeindlichkeit zu punkten („Asylflut stoppen“, „Geld für die Oma statt für Sinti und Roma“), setzte verstärkt auf Anti-Islamismus („Maria statt Scharia“) und versuchte, mit der Forderung „D-Mark statt Europleite“ den eurokritischen Teil der Wähler anzusprechen. Etwas Medienaufmerksamkeit konnte sie nur generieren, als sie kurz vor der Wahl Briefe mit „Rückflugtickets“ an Politiker mit Migrationshintergrund schickte.

Seit der Aufdeckung der terroristischen Anschlagserie des „Nationalsozialistischen Untergrunds“ (NSU) im November 2011 stand die NPD aufgrund ihrer Verbindungen zum Neonazi-Milieu wieder verstärkt im Visier der Öffentlichkeit. Die Diskussion konzentrierte sich schnell auf die Frage, ob man - nach dem gescheiterten Verbotsantrag von 2003 - einen erneuten Anlauf nehmen sollte, die Partei vom Bundesverfassungsgericht verbieten zu lassen. Nach längerer Vorbereitung stellte schließlich der Bundesrat am 3. Dezember den Verbotsantrag. Seine Erfolgsaussichten werden von Beobachtern aufgrund der vom Verfassungsgericht gesetzten hohen Hürden und der im Falle eines Verbots möglichen Klage vor dem Europäischen Gerichtshof für Menschenrechte nicht nur positiv beurteilt. Zudem 
führt ein Verbot der NPD natürlich nicht dazu, dass rechtsextremes Gedankengut aus der Gesellschaft verschwindet, und sogar der parteiförmig organisierte Rechtsextremismus könnte, wenn die bisher völlig erfolglose Kleinstpartei Die Rechte (vgl. Abschnitt 3) als Auffangbecken fungiert, in neuer Gestalt weiterleben.

\subsection{Bayern ist nicht die Bundesrepublik: die Bundesvereinigung Freie Wähler}

Freie Wählergemeinschaften existieren auf kommunaler Ebene bereits seit Beginn der Bundesrepublik. Sie nehmen für sich in Anspruch, keine parteipolitisch ausgerichtete, sondern eine überparteiliche, ausschließlich an sachpolitischen Erwägungen orientierte „Politik mit gesundem Menschenverstand“ zu machen, und sehen sich daher selbst nicht als Partei. Die kommunalen Wählergemeinschaften gründeten schon sehr früh Landesverbände und organisierten sich 1965 bundesweit im Bundesverband „Freie Wähler Deutschland e.V.“ Einige Landesverbände nahmen als politische Vereinigungen oder in Parteiform ohne Erfolg an Landtagswahlen teil, wobei dies unter den Mitgliedern meist umstritten war, weil man damit das eigentliche kommunalpolitische Betätigungsfeld verließ.

In Bayern gelang jedoch 2008 mit sensationellen 10,2 Prozent der Stimmen der Einzug in das Landesparlament, worauf der Bundesverband nach kontroverser Diskussion beschloss, bei der Europawahl 2009 bundesweit anzutreten. Hierzu gründete man im Januar 2009 die Bundeswählergruppe „FW Freie Wähler“. Das Wahlergebnis blieb mit 1,7 Prozent weit hinter den Erwartungen zurück. Dennoch wurde im Februar 2010 die Bundeswählergruppe in die Partei mit dem Namen „Bundesvereinigung Freie Wähler“ umstrukturiert, die seit Juli 2013 Landesvereinigungen in allen 16 Bundesländern besitzt. Diese sind jedoch nicht immer als der „politische Arm" der kommunalen Wählervereinigungen beziehungsweise ihres Landesverbands anzusehen. Die starken baden-württembergischen Freien Wählergemeinschaften zum Beispiel lehnen eine Teilnahme an Wahlen auf höheren Ebenen bis heute vehement ab. Dennoch beschloss die Bundesvereinigung im Juni 2012, bei der Bundestagswahl 2013 anzutreten. Treibende Kraft hinter diesem Beschluss war der Multifunktionär Hubert Aiwanger, Partei- und Fraktionschef in Bayern und Vorsitzender der Bundesvereinigung.

Nach dem Erfolg in Bayern hatte man bei einigen der folgenden Landtagswahlen durchaus gehofft, die Fünf-Prozent-Hürde zu überwinden. Dies hätte die Ausgangsbasis für die Bundestagswahl deutlich verbessert. Das herausragende Ergebnis bei der bayerischen Landtagswahl 2008 war jedoch auf landesspezifische Faktoren zurückzuführen. ${ }^{17}$ Bei den 18 Landtagswahlen bis zur Bundestagswahl erreichten Freie Wählergemeinschaften - mit Ausnahme der Wahl in Thüringen 2009 (3,9 Prozent) - nur Ergebnisse zwischen 0,2 und 2,8 Prozent. Dies dämpfte die Erfolgsaussichten bei der Bundestagswahl, obwohl es gelang, in allen 16 Bundesländern eine Landesliste aufzustellen und die erforderlichen Unterstützungsunterschriften zu sammeln. Es kam daher darauf an, einen Spitzenkandidaten zu präsentieren, der der Partei über Bayern hinaus die notwendige (Medien-)Aufmerksamkeit verschaffen würde, und ein Thema zu finden, das als Alleinstellungsmerkmal im Parteiensystem gelten konnte. Stephan Wehrhahn, Enkel des ersten deutschen Bundeskanzlers Konrad Adenauer, war als Spitzenkandidat vorgesehen, erklärte jedoch im März 2013 noch

17 Vgl. Rainer-Olaf Schultze / Jan Grasnick, Die bayerische Landtagswahl vom 28. September 2008: Betriebsunfall oder Ende eines Mythos?, in: ZParl, 40. Jg. (2009), H. 1, S. 34 - 55. 
vor der offiziellen Nominierung seinen Rücktritt. Somit kam der Partei schon vor der heißen Phase des Wahlkampfes ihr personelles Zugpferd abhanden. Das gleiche geschah mit dem inhaltlichen Alleinstellungsmerkmal. Man setzte darauf, die Partei als bürgerliche Protestalternative gegen den Eurorettungskurs der anderen Parteien zu etablieren. Diese Strategie scheiterte mit der Gründung der AfD, die als neue eurokritische Alternative alle Aufmerksamkeit auf sich zog. Im Wahlkampf spielten die Freien Wähler außerhalb Bayerns, wo eine Woche früher der Landtag gewählt wurde, keinerlei Rolle. Die Bundesvereinigung

\section{Tabelle 1: Kleinstparteien bei der Bundestagswabl 2013}

\begin{tabular}{|c|c|c|c|c|}
\hline & $\begin{array}{l}\text { Zweitstimmen } \\
\text { (in \%) }\end{array}$ & $\begin{array}{l}\text { Erststimmen } \\
\text { (in \%) }\end{array}$ & $\begin{array}{c}\text { Anzahl der } \\
\text { Landeslisten }\end{array}$ & $\begin{array}{c}\text { Anzahl } \\
\text { WK / BL }{ }^{1} \\
\end{array}$ \\
\hline $\mathrm{AfD}^{2}$ & 4,70 & 1,86 & 16 & $158 / 13$ \\
\hline Tierschutzpartei & 0,32 & 0,01 & 5 & $2 / 1$ \\
\hline ÖDP & 0,29 & 0,29 & 8 & $62 / 6$ \\
\hline REP & 0,21 & 0,06 & 10 & $21 / 6$ \\
\hline Die Partei & 0,18 & 0,09 & 5 & $32 / 10$ \\
\hline pro Deutschland & 0,17 & 0,01 & 13 & $3 / 3$ \\
\hline BP & 0,13 & 0,07 & 1 & $11 / 1$ \\
\hline Volksabstimmung & 0,07 & 0,00 & 2 & $2 / 1$ \\
\hline MLPD & 0,06 & 0,03 & 16 & $41 / 14$ \\
\hline Rentner & 0,06 & 0,00 & 3 & $1 / 1$ \\
\hline Vernunft & 0,06 & 0,01 & 4 & $6 / 4$ \\
\hline BIG & 0,04 & 0,01 & 3 & $6 / 2$ \\
\hline $\mathrm{PBC}$ & 0,04 & 0,00 & 2 & $5 / 1$ \\
\hline BüSo & 0,03 & 0,04 & 6 & $38 / 7$ \\
\hline Die Frauen & 0,03 & - & 1 & - \\
\hline Nichtwähler & 0,03 & - & 1 & - \\
\hline Bündnis 21/RRP & 0,02 & 0,01 & 3 & $17 / 5$ \\
\hline Die Violetten & 0,02 & 0,01 & 1 & $5 / 3$ \\
\hline Familie & 0,02 & 0,01 & 1 & $4 / 3$ \\
\hline Die Rechte & 0,01 & - & 1 & - \\
\hline PSG & 0,01 & - & 3 & - \\
\hline B & - & 0,00 & - & $1 / 1$ \\
\hline BGD & - & 0,00 & - & $1 / 1$ \\
\hline DKP & - & 0,00 & - & $6 / 3$ \\
\hline Nein! & - & 0,00 & - & $1 / 1$ \\
\hline
\end{tabular}

1 Anzahl der zugelassenen Kreiswahlvorschläge / Anzahl der Bundesländer mit Kreiswahlvorschlägen.

2 Abkürzungen: AfD = Alternative für Deutschland; Tierschutzpartei $=$ Partei Mensch Umwelt Tierschutz; ÖDP = Ökologisch-Demokratische Partei; REP = Die Republikaner; Die Partei $=$ Partei für Arbeit, Rechtsstaat, Tierschutz, Elitenförderung und basisdemokratische Initiative; pro Deutschland = Bürgerbewegung pro Deutschland; BP = Bayernpartei; Volksabstimmung = Ab jetzt $\ldots$ Demokratie durch Volksabstimmung - Politik für die Menschen; MLPD = Marxistisch-Leninistische Partei Deutschlands; Rentner = Rentner Partei Deutschland; Vernunft $=$ Partei der Vernunft; BIG = Bündnis für Innovation \& Gerechtigkeit; PBC = Partei Bibeltreuer Christen; BüSo = Bürgerrechtsbewegung Solidarität; Die Frauen $=$ Feministische Partei Die Frauen; Nichtwähler $=$ Partei der Nichtwähler; Familie $=$ Familien-Partei Deutschlands; PSG $=$ Partei für Soziale Gleichheit, Sektion der Vierten Internationale; B = Bergpartei, die „ÜberPartei“; BGD = Bund für Gesamtdeutschland; DKP = Deutsche Kommunistische Partei; NEIN! = NEIN!-Idee.

Quelle: Der Bundeswahlleiter (Hrsg.), Wahl zum 18. Deutschen Bundestag am 22. September 2013, Heft 3: Endgültige Ergebnisse nach Wahlkreisen, Berlin 2013. 
war außerhalb Bayerns unzureichend organisiert, chronisch unterfinanziert, erhielt so gut wie keine Medienunterstützung und wurde von den anderen Parteien vollkommen ignoriert. Ihr Wahlergebnis fiel mit 1,0 Prozent entsprechend schlecht aus.

\section{Kleinstparteien bei der Bundestagswahl 2013}

Von den 25 Kleinstparteien, die an der Bundestagswahl 2013 teilnahmen (vgl. Tabelle 1), hebt sich die am 6. Februar 2013 gegründete „Alternative für Deutschland“ (AfD) klar von allen anderen Parteien ab. Mit 4,7 Prozent der Zweitstimmen hat sie die Schwelle zur Repräsentation im Bundestag nur knapp verpasst. Sie ist in allen Bundesländern mit Landeslisten angetreten, was nur einer weiteren Partei - der MLPD - gelang, und hat die mit Abstand größte Zahl von Wahlkreiskandidaten (158 in 13 Bundesländern) aufgestellt. Die AfD ist momentan noch zu den Kleinstparteien zu zählen, weil sie weder auf der Landesnoch auf der Europaebene parlamentarisch repräsentiert ist. ${ }^{18} \mathrm{Da}$ sie wegen der im Mai 2014 stattfindenden EP-Wahl in naher Zukunft mit großer Wahrscheinlichkeit zu den Kleinparteien gehören wird, wird hier näher auf sie eingegangen. ${ }^{19}$

\subsection{Die Aufsteigerin: Alternative für Deutschland (AfD)}

Die Vorgeschichte der AfD 20 begann am 25. März 2010, dem Tag, als Bundeskanzlerin Angela Merkel Vormittags im Bundestag bekräftigte, mit ihr würde es keine direkten Finanzhilfen für den Eurokrisenstaat Griechenland geben, und abends auf dem EU-Gipfel dem ersten Rettungspaket für das Land zustimmte. Diese Festlegung auf den Versuch, den Euro auch unter Inkaufnahme beträchtlicher finanzieller Risiken zu stabilisieren, war das Katalysatorereignis für verschiedene eurokritische Personen und Gruppen, über Formen politischer Intervention und Organisation nachzudenken. Hierzu gehörte - neben Vertretern des Mittelstands in Verbänden und Parteien - eine Gruppe neoliberal ausgerichteter Wirtschaftswissenschaftler um den Hamburger Professor Bernd Lucke, der im Oktober 2010 ein „Plenum der Ökonomen“ initiierte, um wissenschaftlichen Sachverstand gegen die Eurorettungspolitik zu bündeln.

Vor der Verabschiedung des Europäischen Stabilitätsmechanismus durch den Bundestag Mitte 2012 intensivierten die Gegner der Eurorettungspolitik ihre Aktivitäten und gründeten unter anderem das „Bündnis Bürgerwille“ als überparteiliche Sammlungsbewegung. Inhaltlich an die beiden Organisationen anknüpfend, rief Lucke, bis Ende 2011 CDUMitglied, im September 2012 mit anderen Mitstreitern die „Wahlalternative 2013“ ins Leben. Diese trat im Januar 2013 gemeinsam mit den Freien Wählern bei der niedersächsi-

18 Die Gelegenheit dazu bestand auf der Landesebene durch die Wahlen in Bayern und Hessen. In Bayern ist die Partei nicht angetreten, in der gleichzeitig mit der Bundestagswahl stattfindenden hessischen Landtagswahl hat sie 4,1 Prozent erreicht.

19 Ausführlich zur AfD siehe den Beitrag von Rüdiger Schmitt-Beck in diesem Heft.

20 Für eine ausführliche Darstellung der AfD vgl. Oskar Niedermayer, Eine neue Konkurrentin im Parteiensystem? Die Alternative für Deutschland, in: ders. (Hrsg.), Die Parteien nach der Bundestagswahl 2013, a.a.O. (Fn. 14). Zur Vorgeschichte der Partei und zu ihrem Umfeld vgl. auch Alexander Häusler, Die „Alternative für Deutschland“ - eine neue rechtspopulistische Partei? Materialien und Deutungen zur vertieften Auseinandersetzung, Düsseldorf 2013. 
schen Landtagswahl an. Das Ergebnis von 1,1 Prozent erfüllte jedoch nicht die Erwartungen. Daher löste sich die Wahlalternative von den Freien Wählern, und am 6. Februar 2013 wurde die Alternative für Deutschland gegründet.

Ihren ersten, von einer breiten und in großen Teilen auch wohlwollenden Medienaufmerksamkeit begleiteten Auftritt hatte die neue Partei am 11. März, als sie sich der Öffentlichkeit vorstellte. Am 14. April 2013 folgte der Gründungsparteitag in Berlin, auf dem der Vorstand gewählt und Programm sowie Satzung verabschiedet wurden. Erste Umfragen zum breit definierten Wählerpotenzial kamen zu dem Schluss, dass sich ein Viertel der Deutschen unter Umständen vorstellen konnte, eine Partei wie die AfD zu wählen. In den Ergebnissen der Institute zur konkreten Wahlabsicht tauchte die Partei jedoch erst nach ihrem von großer Medienaufmerksamkeit begleiteten Gründungsparteitag auf, und zwar mit nicht mehr als zwei bis drei Prozent. Lediglich ein Institut verortete sie kurzfristig bei vier bis fünf Prozent. In den nächsten vier Monaten blieb die AfD in den Umfragen bei zwei bis drei Prozent stehen. In der heißen Phase des Wahlkampfs erreichte sie jedoch vier Prozent Wählerzuspruch, und ein Institut sah sie kurz vor der Wahl sogar bei fünf Prozent. Bei der Wahl selbst scheiterte sie mit 4,7 Prozent knapp an der Sperrklausel und zog daher nicht in den Bundestag ein. Das Wahlergebnis ist dennoch ein großer Erfolg, denn seit den 1950er Jahren ist es in Deutschland noch nie einer Partei gelungen, kurz nach ihrer Gründung so gut abzuschneiden.

Als Grund dafür ist auf der Angebotsseite des Parteienwettbewerbs zunächst die für eine neue Partei sehr gute Ressourcenausstattung zu nennen. Die AfD schaffte es in Rekordzeit, eine flächendeckende, funktionsfähige Organisationsstruktur und eine tragfähige Mitgliederbasis aufzubauen. Schon vor dem Gründungsparteitag konnten in fünf Bundesländern Landesverbände gegründet werden, die übrigen elf folgten bis Mitte Mai. Zudem hatte die Partei regen Zulauf: Schon Ende März hatte man nach eigenen Angaben 5.000 Mitglieder, Ende April waren es 10.000. Die rasche organisatorische Konsolidierung schuf sehr gute Voraussetzungen für die Überwindung der rechtlichen Hürden zur Wahlteilnahme: Jede politische Vereinigung, die nicht im Deutschen Bundestag oder einem Landtag seit deren letzter Wahl auf Grund eigener Wahlvorschläge ununterbrochen mit mindestens fünf Abgeordneten vertreten war, muss zunächst ihren Wunsch nach Beteiligung an der Bundestagswahl spätestens am 97. Tag vor der Wahl, diesmal also bis zum 17. Juni, gegenüber dem Bundeswahlleiter schriftlich anzeigen. Der Anzeige sind Satzung und Programm sowie der Nachweis über die satzungsgemäße Bestellung des Vorstandes und andere Unterlagen beizufügen. Dies konnte die AfD fristgerecht tun. Der Bundeswahlausschuss entscheidet anhand der Unterlagen, ob er der Vereinigung für die anstehende Wahl die Parteieigenschaft zuerkennt, was jedoch nicht automatisch bedeutet, dass die Partei auch letztendlich an der Wahl teilnehmen kann. Alle Parteien müssen in jedem Bundesland, in dem sie an der Bundestagswahl teilnehmen wollen, die Kandidaten auf ihren Landeslisten von einer Mitglieder- oder Delegiertenversammlung in geheimer Abstimmung wählen lassen. Neue Parteien müssen zudem in jedem Bundesland bis zu 2.000 Unterstützungsunterschriften von Wahlberechtigten aus diesem Land sammeln, um vom jeweiligen Landeswahlausschuss zur Wahl zugelassen zu werden. Diese Erfordernisse erfüllte die AfD bis Mitte Juli ebenfalls in allen Bundesländern, so dass sie flächendeckend an der Wahl teilnehmen konnte.

Auch die personellen Ressourcen auf der Führungsebene trugen zum Erfolg bei. Mit dem ehemaligen Welt-Chefkorrespondenten Konrad Adam und dem ehemaligen Herausgeber der Märkischen Allgemeinen Alexander Gauland war Medienaffinität sichergestellt, und 
mit Bernd Lucke hatte die Partei einen Spitzenkandidaten, der vor allem in der Anfangsphase in den Medien prominent vertreten war und die AfD-Standpunkte eloquent vertrat. Über die Finanzausstattung der Partei ist nur wenig bekannt. Ihre Führung behauptete wiederholt, von Kleinspenden der Mitglieder zu leben, was allerdings erst mit dem ersten Rechenschaftsbericht nachzuprüfen sein wird. Die professionelle und flächendeckende Werbekampagne lässt auf jeden Fall darauf schließen, dass die Partei von Anfang an auf einer soliden finanziellen Basis stand.

Ein weiterer Pluspunkt für die AfD war, dass sie - trotz parteiinterner Streitigkeiten beim Aufbau einiger Landesverbände - in der Außenkommunikation den Wählern überwiegend ein Bild der Geschlossenheit vermitteln konnte und die gesamte Kampagne durch ein funktionierendes strategisches Steuerungszentrum geplant und ausgeführt wurde. Die Führung begegnete zudem dem Erfordernis, schon kurz nach der Parteigründung und vor dem Beginn des Wahlkampfs ein Wahlprogramm vorlegen zu müssen, mit einer dezidierten Willensbildung von oben nach unten: Das nicht einmal vierseitige Programm wurde vom Vorstand verfasst, und auf dem Gründungsparteitag ließ man es ohne Debatte verabschieden.

Inhaltlich hatte die Partei durch ihre Haltung zur Eurorettungspolitik im Wahlkampf ein Alleinstellungsmerkmal. SPD und Grüne kritisierten zwar das Krisenmanagement der Regierung, hatten jedoch im Bundestag alle Entscheidungen mitgetragen und konnten den Wählern kein alternatives Konzept präsentieren. Die Linkspartei hatte zwar im Bundestag die Beschlüsse zur Eurorettung abgelehnt, auch sie kommunizierte den Wählern aber keine Alternative. Die AfD forderte hingegen eine ,geordnete Auflösung des Euro-Währungsgebiets“ durch „die Wiedereinführung nationaler Währungen oder die Schaffung kleinerer und stabilerer Währungsverbünde“, wobei dies durch eine „Änderung der Europäischen Verträge, um jedem Staat ein Ausscheiden aus dem Euro zu ermöglichen“, erreicht werden soll. Weiterhin wurde gefordert, dass „die Kosten der so genannten Rettungspolitik nicht vom Steuerzahler getragen werden“ und die Banken in der Schuldenkrise „ihre Verluste selbst tragen " müssen. ${ }^{21}$

Die Reaktion der anderen Parteien auf die neue Konkurrentin bestand zunächst darin, diese weitgehend zu ignorieren, auch wenn von Anfang an einige mahnende Stimmen laut wurden, die forderten, man müsse sich mit der AfD inhaltlich auseinandersetzen. Dies geschah jedoch den ganzen Wahlkampf über nur am Rande, da den Parteien aus unterschiedlichen Gründen an einer Thematisierung der Europroblematik nicht gelegen war. Eher versuchten es manche mit Ausgrenzung und Stigmatisierung als rechtspopulistische Partei.

Betrachtet man die Nachfrageseite des politischen Wettbewerbs, also die Orientierungen der Wähler, dann wird zunächst deutlich, dass es durchaus ein Wählerpotenzial für eine eurokritische Partei gab: Die Eurokrise und die Eurorettungspolitik waren für die Wähler kurz vor der Wahl das drittwichtigste Thema, über zwei Fünftel waren der Ansicht, dass der Euro für Deutschland eher Nachteile als Vorteile hat, und für ein gutes Drittel war die Eurokrise für ihre Wahlentscheidung sehr wichtig. Über die Eurothematik hinaus verdeutlichen das Wahlprogramm und weitere inhaltliche Aussagen der AfD, dass sie im Sozialstaatskonflikt eine deutlich marktliberale beziehungsweise marktradikale Position und im sozio-kulturellen Konflikt zwischen progressiv-libertären und konservativ-autoritären Werten eine national-konservative Position vertritt. Mit Ausnahme der Haltung zur Immi-

21 Alternative für Deutschland, Wahlprogramm, Parteitagsbeschluss vom 14. April 2013. 
grationspolitik war diese Verortung auf den beiden zentralen Konfliktlinien des deutschen Parteiensystems für die Wähler im Rahmen der Kampagne jedoch nicht klar erkennbar. Daher war die AfD als populistische Protestalternative für Wählergruppen mit unterschiedlichen Orientierungen wählbar, zum Beispiel auch für ehemalige Wähler der Linkspartei.

Auch die Rahmenbedingungen des Wettbewerbs wirkten sich für den Neuling günstig aus. Zwar wurde nach dem anfänglichen Hype durch einen Teil der Medien die Offenheit der AfD nach rechts zunehmend thematisiert; in der Schlussphase des Wahlkampfs entwickelte sich jedoch eine Aufwärtsspirale aus steigenden Umfragewerten und erhöhter Medienaufmerksamkeit. Zudem rückte das Thema Eurorettung durch die Diskussion über mögliche zukünftige Hilfspakete für Griechenland in der zweiten Augusthälfte noch einmal in den Fokus der Öffentlichkeit. Auch in naher Zukunft bieten sich der AfD günstige Rahmenbedingungen für eine Etablierung im Parteiensystem: Im Mai 2014 ist Europawahl, bei der das Europathema sehr viel prominenter sein wird als bei der Bundestagswahl und bei der in Deutschland zudem keine Sperrklausel mehr gelten wird.

Den günstigen Rahmenbedingungen stehen jedoch innerparteiliche Probleme entgegen, die sich nach der Bundestagswahl deutlich verschärft haben. Bei einigen Politikern der Konkurrenzparteien und in einem Teil der Medien galt die AfD von Anfang an als rechtspopulistisch. In der Parteienforschung ist man jedoch weit überwiegend der - auch vom Verfasser vertretenen - Meinung, dass es für eine eindeutige Einordnung der Partei aufgrund ihres ambivalenten Erscheinungsbildes momentan, das heißt kurz nach der Bundestagswahl, noch zu früh ist. ${ }^{22}$ Aus dem bisher noch sehr kurz gehaltenen Programm lässt sich eine rechtspopulistische Ausrichtung nicht eindeutig ableiten. Im Rahmen der soziokulturellen Konfliktlinie vertritt die AfD eine national-konservative Position, die sich zum Beispiel im traditionellen Familienbild zeigt. Auch in der Immigrationspolitik wird dies in der Forderung nach einem „Einwanderungsgesetz nach kanadischem Vorbild“, also einem Punktesystem nach Qualifikation für den deutschen Arbeitsmarkt, deutlich. Dort findet sich jedoch auch die in rechtspopulistischen Kreisen erhobene Forderung, ,eine ungeordnete Zuwanderung in unsere Sozialsysteme muss unbedingt verhindert werden "23. Zum einen zieht die AfD enttäuschte Aktivisten aus einer Reihe von rechtspopulistischen und auch rechtsextremen Kleinparteien an, die in der neuen Partei größere Chancen zur Verwirklichung ihrer Ziele sehen und sich zuweilen auch lautstark bemerkbar machen. Zum anderen bemüht sich die Parteiführung, mit deutlichen Worten und Abgrenzungsbeschlüssen solche Personen aus der Partei fernzuhalten. Einerseits werden Bernd Lucke und seine Mitstreiter von rechts wegen ihrer europakritischen, aber nicht europafeindlichen Haltung angegriffen, andererseits wird in rechten Postillen Werbung für die AfD gemacht. Innerparteilich eskalierten nach der Bundestagswahl in verschiedenen Landesverbänden personelle Streitigkeiten und in der Gesamtpartei der Richtungskampf um die inhaltliche Positionierung, der über die Zukunft der AfD entscheiden wird. Wenn es ihr gelingt, sich als national-konser-

22 Vgl. zum Beispiel Alexander Häusler, a.a.O. (Fn. 20); Viola Neu, Hidden Champions oder ewige Verlierer - die „sonstigen“ Parteien bei der Bundestagswahl, in: Eckhard Jesse / Roland Sturm (Hrsg.), Bilanz der Bundestagswahl 2013, Baden-Baden 2014 (im Erscheinen); Frank Decker, Attraktiv für Deutschland?, in: Berliner Republik, Heft 3/2013, http://www.b-republik.de/archiv/ attraktiv-fuer-deutschland (Abruf am 1. Juli 2013). Eine andere Position vertritt Andreas Kemper, Rechte Euro-Rebellion: Alternative für Deutschland und Zivile Koalition e.V., Münster 2013.

23 Programm der AfD, a.a.O. (Fn. 21). 
vative und marktliberale Partei mit klarer Abgrenzung zum Rechtspopulismus zu verorten, kann sie auf der sozio-ökonomischen Konfliktlinie der FDP und auf der sozio-kulturellen Konfliktlinie der Union Konkurrenz machen und sich damit einen Platz im Parteiensystem sichern. Wenn nicht, wird sie wohl das Schicksal der bisherigen rechtspopulistischen Kleinund Kleinstparteien erleiden, die alle wieder von der Bildfläche verschwunden sind.

\subsection{Die übrigen Kleinstparteien}

Die anderen Kleinstparteien haben Zweitstimmenanteile bis 0,3 Prozent erreicht und bei den Erststimmen meist noch schlechter abgeschnitten. Bis auf eine linke (MLDP) und zwei rechte (pro Deutschland und die Republikaner) ideologische Randparteien konnten sie nur in relativ wenigen Bundesländern die notwendigen Unterstützungsunterschriften für ihre Listen sammeln. In jeweils nur einem einzigen Bundesland traten sechs Parteien an, darunter sowohl neue Gruppierungen wie die am 27. Mai 2012 von neonazistischen Aktivisten und ehemaligen DVU-Mitgliedern gegründete Die Rechte als auch schon länger existierende Parteien wie die 1995 gegründete feministische Partei Die Frauen. Die einzige „echte“ Regionalpartei ist die Bayernpartei, die für einen eigenständigen bayerischen Staat kämpft.

Nur mit Wahlkreisvorschlägen nahmen vier Parteien teil: Die 1966 als Nachfolgeorganisation der KPD gegründete Deutsche Kommunistische Partei stellte sechs Wahlkreiskandidaten in drei Ländern auf. Die anderen drei Parteien konnten nur die minimalste Form der Wahlteilnahme durch die Präsentation eines Kandidaten in nur einem Wahlkreis realisieren. Neben der rechten ideologischen Randpartei Bund für Gesamtdeutschland waren dies die skurrile, am 1. April (!) 2012 gegründete Nein!-Idee, die jedem Menschen das Recht zusprechen will, „Nein“ zu sagen, ohne dabei nach dem Grund zu fragen, und die einen noch deutlicheren Spaßcharakter tragende Bergpartei aus Berlin-Kreuzberg.

Eine Sonderstellung unter den Spaßparteien nimmt die 2004 von Redakteuren der Satirezeitschrift Titanic gegründete Die Partei ein, die die satirische Parodie von Inhalten und Methoden der anderen Parteien mit zuweilen auch einmal ernsthaften politischen Positionen verbindet. Trotz oder wegen dieser Ausrichtung konnte sie 2011 bei der Landtagswahl in Hamburg 0,7 Prozent und bei der Berliner Abgeordnetenhauswahl sogar 0,9 Prozent der Stimmen erzielen.

Neben der Partei Die Frauen will eine Reihe weiterer Klientelparteien bestimmte Bevölkerungsgruppen vertreten. Zwei Parteien - Rentner und Bündnis 21/RRP - haben die Interessen der Rentner und Pensionäre im Blick; die Familien-Partei will die Familie besser schützen; die BIG setzt sich als multikulturelle Partei für die Eingliederung von Personen mit Migrationshintergrund ein; die Partei der Nichtwähler will den Wahlverweigerern eine Alternative bieten, und die Tierschutzpartei kämpft für die Aufnahme des Tierschutzes in das Grundgesetz.

Die Tierschutzpartei, die bei den letzten Landtagswahlen in drei Bundesländern Ergebnisse zwischen 1,5 und 2,1 Prozent erzielt hat und dadurch an der öffentlichen Parteienfinanzierung teilnimmt, konnte 0,3 Prozent der Stimmen gewinnen. Dies gelang außer ihr nur noch der ÖDP. Die konservative Naturschutzpartei hat ihren klaren regionalen Schwerpunkt in Bayern, wo sie bei den Landtagswahlen regelmäßig Ergebnisse um zwei Prozent erreicht.

Die übrigen Kleinstparteien gehören mit zwei Ausnahmen zu den weltanschaulichen Nischenparteien: Die Partei der Vernunft fordert die allmähliche Eindämmung des Einflus- 
ses der Parteien und des Staates; die Bürgerrechtsbewegung Solidarität verkündet seit Jahrzehnten unter wechselnden Namen (EAP, Patrioten) die Lehre des amerikanischen Politikers Lyndon LaRouche, die orthodox-christliche PBC will biblische Grundsätze in der Gesellschaft verankern, und Die Violetten wollen Spiritualität und Politik vereinen. Die trotzkistische PSG hingegen ist eine linke ideologische Randpartei. Die Partei „Ab jetzt ... Demokratie durch Volksabstimmung - Politik für die Menschen“, die bis 2007 unter dem Namen „Ab jetzt ... Bündnis für Deutschland Liste: Gegen Zuwanderung ins ,Soziale Netz “" kandidierte, stand bis 2006 wegen des Verdachts rechtsextremer Bestrebungen unter Beobachtung des nordrhein-westfälischen Verfassungsschutzes. Die neuere Programmatik konzentriert sich jedoch auf die Forderungen zur Stärkung der direkten Demokratie.

\section{Die Diskussion nach der Wahl}

Die Bundestagswahl 2013 war hinsichtlich der Stärke der Klein- und Kleinstparteien eine Ausnahmewahl, da zwei Parteien die Fünf-Prozent-Hürde nur knapp verfehlten. Dennoch begann nach der Wahl eine Diskussion über den „großen demokratischen Flurschaden“24, der befürchtet wird, weil 6,9 Millionen Wählerstimmen bei der Mandatsverteilung nicht berücksichtigt wurden. Viele Beobachter sehen darin eine massive und in Zukunft nicht mehr hinnehmbare Verletzung des durch das demokratische Gleichheitsprinzip geforderten gleichen Erfolgswerts einer jeden Wählerstimme. Die Fünf-Prozent-Hürde erscheint ihnen zu hoch und ihre Absenkung geboten. ${ }^{25}$ Angesichts der Tatsache, dass die Wahlergebnisse der meisten Kleinstparteien bisher immer deutlich unter fünf Prozent geblieben sind, lässt man auch das Argument nicht mehr gelten, es bestünde die Gefahr einer zu starken Fragmentierung des Parlaments mit ihren negativen Auswirkungen auf die Bildung und Stabilität von Regierungen. Gestärkt werden die Kritiker auch durch das Bundesverfassungsgericht, das im Februar 2011 für Europawahlen jegliche Sperrklauseln für unzulässig erklärt hat.

Eine Herabsetzung der Sperrklausel zum Beispiel auf drei Prozent, wie sie der Bundestag nach dem ersten Urteil des Bundesverfassungsgerichts von 2011 zur Aufhebung der FünfProzent-Hürde bei Europawahlen für diese Wahlen beschlossen hatte, würde nach den bisherigen Erfahrungen wohl tatsächlich nicht zu einer dramatischen Ausweitung der Zahl der im Bundestag vertretenen Parteien führen. Die schlechte Ausstattung mit finanziellen, organisatorischen und personellen Ressourcen, das meist fehlende inhaltliche Alleinstellungsmerkmal beziehungsweise dessen Vereinnahmung durch die größeren Parteien, der fehlende Rückhalt in der Bevölkerung dadurch, dass die aufgegriffenen politischen Inhalte keine neuen, zentralen gesellschaftlichen Konfliktlinien repräsentieren, und die nicht erfolgende oder nach dem Anfangshype schnell wieder abnehmende Medienunterstützung werden wohl auch in Zukunft dafür sorgen, dass selbst ein Wahlergebnis von drei Prozent bei Bundestagswahlen für die Kleinstparteien in der Regel unerreichbar bleibt.

24 Melanie Amann / Thomas Darnstädt / Dietmar Hipp, Demokratischer Flurschaden, in: Der Spiegel vom 25. September 2013, S. $44-45$.

25 Vgl. zum Beispiel das Interview mit dem Rechtswissenschaftler Ulrich Battis im Deutschlandradio Kultur, „Drei Prozent wäre gerechter als fünf Prozent“, 24. September 2013, http://www. deutschlandradiokultur.de/drei-prozent-waere-gerechter-als-fuenf-prozent.1008.de.html? dram:article_id=262858 (Abruf am 25. September 2013). 